Kajian Malaysia, Vol. 37, No. 2, 2019, 75-94

\title{
STUDY ABROAD AND BEHAVIOURAL CHANGES: THE CASE OF MALAYSIAN LEARNERS OF JAPANESE
}

\section{Wong Ngan Ling* and Emily Lau Kui-Ling}

Faculty of Languages and Linguistics, University of Malaya, Kuala Lumpur, MALAYSIA

*Corresponding author: nlwong@um.edu.my

Published online: 20 November 2019

To cite this article: Wong, N.L. and E. K-L. Lau. 2019. Study abroad and behavioural changes: The case of Malaysian learners of Japanese. Kajian Malaysia 37(2): 75-94. https://doi.org/10.21315/ $\mathrm{km} 2019.37 .2 .4$

To link to this article: https://doi.org/10.21315/km2019.37.2.4

\begin{abstract}
Student mobility and enculturation are important keywords in today's context of tertiary education. This is because university students are expected to acquire various soft-skills and competency in their educational pursuits, besides securing a degree. Aiming at understanding how studying abroad can enhance these skills and competency, this study used self-narratives as an approach to elicit information from 12 students who had studied abroad in Japan for a year. Specifically, this study examines what they learnt and how their exposure through intercultural communication in the host country had impacted their real-life experiences in terms of interactional behavioural changes. The participants' perspectives indicated that they had improved under the mobility programmes in terms of language proficiency, enculturation, self-dependence and self-development. The outcome noted from the study will be of benefit to educators who can use this information as recommendations to support students in utilising their knowledge and intercultural skills for employability purposes.
\end{abstract}

Keywords: behavioural changes, Malaysian learners of Japanese, intercultural competency, self-narrative, study abroad

\section{INTRODUCTION}

Student mobility relates to work or study abroad opportunity for both the undergraduate and postgraduate students whilst undertaking their degree programme. Mobility programmes range from bilateral (home and host universities

(C) Penerbit Universiti Sains Malaysia, 2019. This work is licensed under the terms of the Creative Commons Attribution (CC BY) (http://creativecommons.org/licenses/by/4.0/). 
with exchange students); inbound (students from overseas universities who wish to study in host universities), outbound (our students who wish to study overseas) to one-way study abroad. Study abroad is a fee paying programme for either short term (one semester) or long term (one academic year at the host universities).

Student mobility programmes have been perceived as having positive impacts on student's personal development such as gaining more self-confidence, self-awareness, independence, flexibility and adaptability towards cultural differences (Benjamin 2005). Bennett (2004) reported that students become culturally competent after experiencing new cultures as they are adept to interact with people who come from diverse cultural backgrounds and upbringings. Messelink, Maele and Oatey (2015) contend that mobility is an effective way of enhancing intercultural understanding and fostering deeper language learning and improving interpersonal skills among youths, and this skill is highly appreciated by the labour market today. In Europe, mobility programmes such as the Erasmus mobility programme were introduced in 1987 to enrich opportunities for cultural exchange and for professional and personal experience for students within the European Union (Juvan and Lesjak 2011). Since then, studies focusing on international student mobility have gained popularity (Brooks and Waters 2009; 2010; 2011; Dervin and Layne 2013; Suzanne 2015). In 2014, the Erasmus programme was superseded by Erasmus+ (EU's Programme for education, training, youth and sport), whereby students are allowed to do study abroad for up to 12 months. It is expected that 4 million people (students and academicians) will benefit from Erasmus+ (Eurostat 2019).

In accordance with the global trend and movements, many Asian educational institutions, including those in Japan, Korea and Malaysia have also started planning and promoting student mobility programmes through various channels. A case in point is the 3rd EU-Malaysia Higher Education Conference, which was themed "Cooperation in Mobility between Students and Academics" that was held in the University of Malaya on 14 March 2016 to collaborate on mobility exchanges and research partnerships. University of Malaya (hereafter UM) created its strategic plan of 2011-2015 focusing on teaching, learning and globalisation. Among these strategies, three are related to student mobility: to ensure quality incoming students from diverse backgrounds and countries, to increase opportunities for exchange through the Students Mobility Programme so as to expand student horizon, and to improve employability by enhancing their soft-skills and give greater exposure to real-world experiences (University of Malaya Official Website 2016a).

With the strategic plan that supports international research collaboration and student mobility, UM has signed 456 memorandums of understanding (MOU) and memorandums of agreement (MOA) with other local and international organisations in the year 2012 (University of Malaya Official Website 2012). The 
present research was conducted to understand the development of the students who are involved in the outbound and inbound programmes of the university, and the student exchange inbound programme that was offered by the Ministry of Education, Culture, Sport, Science and Technology (MEXT, Japan) and Japanese public and private universities which have MOA and MOU with UM and incorporated Foundations such as Heiwanakajima Foundation (HNF) and Japan Students Service Organisation (JASSO).

\section{LITERATURE REVIEWS ON STUDENT MOBILITY, INTERCULTURAL COMPETENCE AND EMPLOYABILITY}

Yorke (2006) defines employability as a set of achievements: "skills, understanding and personal attributes" that relate to employment (as cited in Messelink, Maele and Oatey 2015, 7). In job interviews held at international organisations, it is noted that employers place a high value on the intercultural competence of the students they have observed and this includes their ability to understand matters from different cultural contexts and viewpoints, ability to demonstrate respect for others, and whether they possess an open mind to new ideas and ways of thinking (Anderson et al. 2006). However, some research reveal that not all employers are aware of the skills students acquire through international mobility programmes because students are not always capable of verbalising what they have learned in ways that are relevant to the workplace. In solving this problem, Messelink, Maele and Oatey (2015) conducted a study on mobility to give suggestions to intercultural educators in setting learning objectives for mobile students. They also proposed that intercultural educators pay attention to what students are actually learning (instead of what they should learn) in mobility programmes as well as to give assistance to students in conveying the intercultural skills which they had acquired for employability purposes. According to the European Commission 2014 annual series reports on the evaluation of education and training systems across Europe, language competencies contribute to mobility and employability of European citizens and facilitate intercultural dialogue (Eurodesk 2015, 7).

European Youth Forum 2013 reported a survey done on the impact of non-formal education in 254 youth organisations on young people's employability which concluded that long term and constant exposure and participation in youth organisations resulted in high soft-skills development. This study also revealed that experience in non-formal education activities abroad enabled young people to develop higher language skills and intercultural and leadership skills which are valued by employers.

A study done on the employability of international graduates educated in Finnish Education Institutions narrated that "international graduates were 
considered to be flexible, highly adaptive and in possession of good intercultural skills owing to their experience of living and studying away from home" (Eurodesk 2015). According to the same study, apart from subject-specific skills and competencies, study abroad experience can be one of the ways (other than internship and language studies) in developing international students' potential and becoming more employable. In fact, research on skills most anticipated by multinational companies for their future employees is bent on "graduates with internationally compatible skills such as second language fluency and knowledge on international cultures and custom would be vital to the continued profitability of the firm and, by extension, the nation" (Salisbury 2011, 2). For this reason, study abroad programme providers are urged to consider whether their programmes considerably improved their participants' intercultural competency skills.

A huge repertoire of theoretical and empirical research has been conducted on the subject matter of intercultural competence, however, there is no full agreement on a single consensus definition to describe and measure intercultural competence. Salisbury's (2011, 12-13), following Deardorff $(2004 ; 2006)$ defines intercultural competence as:

A process orientation that is organised into two levels or stages - an individual level and an interactional level, each containing two separate steps. Within the individual level, the first step requires that one possess attitudes of respect or value for other cultures, openness and the ability to withhold judgement, and curiosity to discover while tolerating ambiguity. The second step requires that one develop specific knowledge and comprehension that would include cultural self-awareness, deep cultural knowledge, and sociolinguistic awareness. [...] At the interactional level this definition of intercultural competence differentiates between two types of expected outcomes: internal and external. The internal outcomes demonstrating intercultural competence are an informed frame of reference shift that would come through increased adaptability, flexibility, ethno relativism, and empathy. The external outcome expected of this process orientation is that all of these developmental gains are integrated holistically so that the individual demonstrates effective and appropriate communication and behaviour in an intercultural situation.

Salisbury's conceptualisation of intercultural competence is divided into two stages: individual and interaction. The individual stage comprises two sets of attitudes or attributes. Set One: respect or value, non-judgemental and curiosity for other cultures; and Set Two: the critical aspects of knowledge and comprehension where a contextual understanding gained in one setting can be transferred in a new setting. Based on Salisbury's (2011) definition, the present study traces the behavioural changes at both individual and interactional levels. This is one of the 
pioneering research done on behavioural changes of Malaysian students who went to Japan under the one-year study abroad programme.

\section{OBJECTIVES OF THE STUDY}

This study analyses the self-narration extracted from 12 Malaysian respondents who had travelled to study in Japan for a year in Japanese universities of their choices. This study aims to see how their exposure through intercultural communication in the host country has impacted their real-life experiences in terms of interactional behavioural changes as well as the development of their personal socio-pragmatic skills.

Based on Salisbury's conceptualisation of the two stages of intercultural competence at the individual and interactional levels, this study analyses how and what international students are learning in authentic interactions. This can provide pertinent insights into how students grow as a person at the individual level and what they have benefited from the programme after their 12-month stay in Japan. It provides a platform for understanding their behavioural changes and for educators, how living abroad experience enhances the students' knowledge and intercultural skills for future employability purposes. It is deduced that the interactional skills which they had acquired during the study abroad programme will lead them to better employability opportunities.

\section{DATA COLLECTION}

This study describes a research project that tracks the development of respondents' intercultural awareness over 12 months of staying in Japan from inside and outside the classroom. Self-reported narrations are used to elicit information from 12 students who majored in the Japanese language study programme after four to eight weeks they returned from Japan. Five students went to Japan in the academic year of 2013-2014 and seven students went in the academic year of 2014-2015.

The self-report narrations survey was set to 13 questions to gauge information on what have students learned during the one year stay in a foreign country based on five domains: (1) Japanese language learning including useful grammar and structures, lecturer and students relationship; (2) Japanese culture learning in general such as interpersonal relationships, daily habits, study/working attitudes; (3) How they react when they encounter problems; (4) What are the merits and demerits of the study abroad programme; and (5) What is the changed and unchanged self and one open-ended question to express what they want to further express as the last question. The respondents were given three to five 
days to write the report and send it back to the researcher via email. They were informed that anyone who did not want to participate was free to opt out. No one opted out and no material reward was offered for participation. The two cohorts of respondents were asked to answer the same questions after one to two months after their return from Japan.

All of them were sponsored either by the Japanese Government (MEXT) scholarship or a public-service corporation such as Heiwa Nakajima Foundation (HNF). These students were provided the opportunity to experience the Japanese language learning and Japanese culture first hand through attending classes in the host universities. Some were given the experience of being in a home stay for a few days with Japanese host families.

Details of the respondents, type of scholarship received and host universities are listed in Table 1.

Table 1: Details of the respondents, type of scholarship received and host universities

\begin{tabular}{cccc}
\hline Respondents & Period of stay & Type of scholarship & Host university in Japan \\
\hline K & $9.13-9.14$ & MEXT & Tsukuba \\
A & $9.13-9.14$ & MEXT & Kyushu \\
O & $9.13-8.14$ & MEXT & Doshisha \\
Y & $9.13-8.14$ & HNF & Waseda \\
N & $10.13-9.14$ & MEXT & Utsunomiya \\
P & $9.14-9.15$ & MEXT & Hitotsubashi \\
E & $9.14-8.15$ & MEXT & Hokkaido \\
CU & $9.14-8.15$ & MEXT & Hokkaido \\
CH & $9.14-8.15$ & MEXT & Soka \\
S & $9.14-8.15$ & MEXT & Waseda \\
C & $10.14-9.15$ & MEXT & Tottori \\
YV & $9.14-9.15$ & HNF & Chiba
\end{tabular}

Note: MEXT - Ministry of Education, Culture, Sport, Science and Technology, Japan; HNF - Heiwa Nakajima Foundation

\section{DATA ANALYSIS AND FINDINGS}

Apart from asking students' perception on what they have learned and benefited from the study abroad programme in Japan, this study takes a step further to investigate whether the experience of a year study abroad has caused any positive behavioural changes in their daily lives. It is believed that thinking critically about self-behaviour in a constant immersion of intercultural interactional environment 
for a year may boost up the intercultural competence and personal development even further. In line with Benjamin's (2005) notion that intercultural competence and sensitivity toward self-behavioural changes are interconnected, this study extends it by providing actual intercultural intellectual and behavioural developments which may lead to higher possibility of employability.

In the following analysis, relevant statements made by respondents are quoted and their names were anonymously coded using alphabet. The Japanese words used by the respondents are translated into English for ease of reference.

On the whole, the findings summarise and discuss the respondents' extralinguistic aspects on the individual and interactional levels (Salisbury 2011). These aspects can be related to a better self-development and their intercultural competency, specifically, intercultural skills that are related to appropriation as well as the internalisation of positive values from by the target culture. Again, this is believed to aggregate to positive behavioural changes which may lead to better employability prospects.

\section{INDIVIDUAL LEVEL: CULTURAL DIFFERENCES BASED ON RESPONDENTS' OBSERVATIONS}

Respondents held certain perceptions towards the Japanese people and its society before they went to Japan. On some occasions, they were shocked or confused when their expectations turned out to be the opposite ones. For instance,

Observed that young university Japanese are less punctual and some skipped classes as well. (Respondent $\mathrm{S}$ )

This is atypical of the common perception of the Japanese being a very punctual society. In the classroom, several respondents observed the positive and negative sides of learning attitudes from their Japanese and other course mates who were from different parts of the world. Examples of positive observations are from Respondents $\mathrm{S}, \mathrm{N}$ and $\mathrm{P}$.

The relationship between students and lecturers are [sic] more formal. Lecturers give students much more space to plan their own studies. (Respondent S)

They (the Japanese) are very respectful to their teacher and someone older than them. They will greet them and speak careful when someone is higher position than them. I think that it is very professional to be able to switch self so fast. (Respondent $\mathrm{N}$ ) 
Japanese students' opinions are rational and coherent supported with fact and statistics. (Respondent P)

As Salisbury (2011) pointed out, these students experienced respect or value for other cultures at the individual level. The negative observations were also noted as it was mentioned that,

Japanese people conform to social norm too much - but this attitude works during disaster. (Respondent $\mathrm{S}$ )

The second clause balances out the critique of conforming to social norms as during the earthquake. For example, Japanese people are trained from primary school on what to do and act when such natural disasters happen. This goes to show there is a sense of openness and the ability to withhold judgement. In fact, Respondent $\mathrm{S}$ also acknowledged other foreigners' good and bad attitudes,

My foreigner course mates' Japanese level are higher than me ... they are very diligent ... They will check out for more info even after the lecturer explained it. They have a very strong curiosity in them. One bad thing is they like to do their things on their own instead of in a group. (Respondent S)

Outside the classroom, through part time jobs or club activities interactions, respondents acquired social knowledge and learned to be appreciative of others.

Through my part time job, I have come to appreciate the hard work of foreign labourers a lot more, and also those who are in the service industry" and "I once imagined the Japanese social system to be a very rigid one, especially in work places and university circles (club activities). But after joining circles and working there, I found that there are a surprising number of places where this type of relationship is quite relax [sic]. (Respondent S)

On the other hand, they had deep admiration for Japanese work ethics,

I respect Japanese work commitment - e.g. say thank you to every bus passenger, guard: stand up straight while on work [sic]. (Respondent O)

Deardorff (2004) described intercultural competence as a multi-faceted capacity of valuing cultural diversity and observing important factors of social interactions, it can be deduced from the statements that respondents at their individual observation levels, are capable to scrutinise cultural differences while learning and socialising with their course mates. Many of them are sharp in 
picking up attitudes which are either in their interest or of their concern while some are Japanese culture-specific situations or different from their expectations. This spurred them to think analytically or to understand the situation. Respondent $\mathrm{Y}$, for instance, had a new understanding of politeness as not just a form of respect, but also a distancing strategy.

Their politeness (Japanese people) is not just as a way to show respect, but is also a tool to keep the distance between the speaker and the listener. This is very confusing for a foreigner and sometimes I felt that they are living with a mask. (Respondent Y)

This distancing strategy was also experience by another person,

Some of the Japanese people make distant to others. (Respondent O)

Several respondents commented that,

Japanese people are not communicating their true feelings. (Respondents $\mathrm{C}, \mathrm{N}, \mathrm{Y}, \mathrm{E}$ and $\mathrm{P}$ )

One even added that,

They (the Japanese) should tell their own opinion clearly, this may reduce suicide and depression. (Respondent $\mathrm{P}$ )

Salisbury $(2011,13)$ informs that at the individual level, the second step requires that "one develop specific knowledge and comprehension that would include cultural self-awareness, deep cultural knowledge, and sociolinguistic awareness". The self-awareness was related the daily expressions used by their Japanese coursemates with literal meaning as a kind of politeness to end a conversation,

I learned the word "mataasobou", is a kind of conventional expression or polite way of ending a meeting/event not the literal meaning to meet again some other time. (Respondent A)

The common social problem in Japan such as bullying and alienating certain people they cannot get along with from a group are difficult to be observed unless a person stays long enough in the particular place,

I get to know the social problem - bully. (Respondents CU) 
Japanese people have prejudice against certain people. (Respondents CU and $\mathrm{CH}$ )

The effort to get accepted into a club activity was not rewarded as the statement narrated,

Attending the (club) activities twice a week for more than half year, doesn't make me feel being accepted as friend even until the end of my exchange programme. (Respondent $\mathrm{CH}$ )

From the individual level observations, four positive aspects are observed: Firstly, the lecturer-student relationship is quite formal and this reflects the elderly respect. Secondly, the situational register adaptation is internalised. For instance, they will become more relaxed if their relationship with the interlocutor is close. Thirdly, some of them observed Japanese good working attitude through part time jobs and finally, through group discussions, they are aware of the way to consolidate one's opinions with fact and statistics.

Nevertheless, the respondents managed to observe the negative aspects of the society such as incidents of bullying, the difficulty to be accepted as a member of certain groups, and the superficial "praise culture" which essentially hides one's feeling as Respondent N shared that,

They have this overly praise culture that I do not like because I could not differentiate if they really mean it or not. (Respondent $\mathrm{N}$ )

These encounters made them think of the social problems critically and try to come to an understanding of how their stereotypical perceptions of the Japanese are a reflection of their intercultural myopia. How much they have learned from these observations is beyond the scope of this study but their ability to discern various attitudes in different contexts indicated their sensitivity toward culture and willingness to tolerate by bottling up to themselves. Notwithstanding the negative aspects, the following self-reported behavioural changes provide meaningful insights of a long-term study abroad programme. Behavioural changes of the respondents can be noticed through self-report of personal development and their intercultural competence skills are acquired through social interactions with their classmates, club activity participations and part-time jobs.

\section{Interactional Level: The Internal Outcomes}

Apart from language acquisition, respondents thought that they have learned a lot in their Japanese language classes from their various cultural background 
classmates. They learned to be more tolerant with people from different countries as Respondent $\mathrm{O}$ expressed,

Interacting with different people from different country and cultural background allows you to learn to tolerate people that hold different opinion. (Respondent O)

The attitudes of openness to others in terms of accepting different cultures as expressed by Respondent $\mathrm{CU}$, and paraphrasing expressions to suit the respective interlocutors demonstrated intercultural competence learned through an informed frame of reference shift by Respondents $\mathrm{C}$ and $\mathrm{CH}$.

I have also come to accept the culture of a different country. (Respondent $\mathrm{CU})$

I also have more courage to use Japanese. Whenever there is a word I cannot remember, I try saying it in a different way. (Respondent C)

I learned how to reject people in a polite way. (Respondent $\mathrm{CH}$ )

By being able to be open, accepting and even rejecting people in a polite manner, they have shown an increased reference shift by their adaptability and flexibility skills. In fact, the internal outcomes of intercultural competency under ethno relativism and empathy are evidence of their internalising interpersonal social skills such as the technique of praising, consideration of others' feelings and appreciation of others.

I even learned Japanese people's praising skill. This might help me in the future when working and making new friends. (Respondent $\mathrm{N}$ )

I have adopted some of the Japanese thinking, such as to humble myself more and not to talk too straightforwardly towards people. I think I have become more emotionally sensitive as I care a lot about people's thinking. (Respondent CU)

Many respondents have become more aware of their own behaviour during interactions. They observed other people from other cultures by making comparisons and demonstrated appropriate communication behaviour during interactions and learned how to refuse someone politely,

I found that I try to consider the others' feeling when I want to refuse someone's invitation. (Respondent E) 
Respondent $\mathrm{S}$ learned the way to reduce miscommunication during interaction,

I think I have learned to communicate with people better through this programme ... I feel that I now have a better grasp of how to communicate ideas with different people and miscommunication is kept at a very minimal level or none at all. (Respondent $\mathrm{S}$ )

Respondent Y realised that being a good listener is important,

I will listen more than talk more now, because I realise the importance of listening to what others tells you. (Respondent Y)

Respondent $\mathrm{CH}$ became aware that showing negative emotions during interaction may give negative impact to the interlocutor,

I am not showing each and every emotion on my face as I was ... I think not letting my negative emotion to affect others is important. (Respondent $\mathrm{CH}$ )

Immersed in Japanese society for a year, the enculturation is realised through not only changes in the way they think, but physical movement is also affected. The adaptive manner of the respondents have resulted in unconscious behavioural changes but they did not realise it until it was pointed out by others. Usually, to greet a person we meet, Japanese people bow instead of shaking hand. This cultural behaviour is embodied in their daily lives after returning from Japan,

My friend said I bow too much. (Respondents $\mathrm{C}$ and $\mathrm{CU}$ )

From the appearance aspect, some of the respondents who care little of their appearance seemed to pay more attention to their looks.

I become a little bit more fashionable and attend to our own appearance more. (Respondent CU)

One of my Japanese girl friends told me that it is rude to go out without wearing any make up thus, I also learned how to have a good appearance. In Malaysia, I will not care much about my appearance and do not even bother to wear make-up. (Respondent A)

Having the opportunity of staying overseas for a year and immersing in many intercultural communication with friends, classmates and colleagues at the part-time job, not only is self-development experienced at the individual level, but 
appreciation of being a Malaysian has grown as well. As said by Salisbury, "an informed frame of reference shift" occurred as part of self-discovery growth and testified by Respondent $\mathrm{O}$,

Studying abroad also makes you realise how great your own country is. For example, Malaysians are generally friendly and warm and you will receive a smile even from people you do not know when walking on the streets, we have variety of foods in Malaysia, and we have less language barriers whether talking to westerners or Asians. (Respondent $\mathrm{O}$ )

In line with this, Respondent E realised that being a Malaysian is great,

I love Malaysia more than before after discovering some good points ... I was praised by my course mates for being able to speak three languages, Malaysians are international. Malaysian languages are beautiful. (Respondent E)

Respondent E gained the courage to speak English with people from other countries who are either not proficient or do not have the environment to speak English frequently as Malaysians reported that,

I feel that I became braver and confident to speak English with others. (Respondent E)

The positive attitudes of Malaysians such as friendliness, adaptiveness to other cultures and open mindedness are being perceived and captured during interaction with people from other cultures as stated,

Malaysians are adaptive and open to other cultures. (Respondent CU)

People are often with smiling faces, friendly. (Respondent Y)

However, Respondent $\mathrm{O}$ was upset when comparing Malaysians with Japanese in terms of politeness and cleanliness, as uttered in her own words,

Making comparison between Japan and Malaysia - become disappointed about Malaysian attitude particularly related to politeness, cleanliness. (Respondent O)

Being brought up in a multilingual society, the respondents did not realise their advantage of speaking three languages until they met people who were from a monolingual society. Showing smiling faces to others as friendly gesture, accepting a different culture openly seems to become a social norm subconsciously. 
The aptitude of being able to discern, analyse and appreciate can be deduced as a holistic growth that has taken place as a person experienced the interactional communications they had experienced in Japan.

\section{Interactional Level: The External Outcomes}

As highlighted by Salisbury, an individual will show appropriate and effective communicative behaviour in an intercultural setting when they have internalised these developmental gains. Some of these personal developmental qualities were encapsulated in their sharing threads, in terms of personal growth.

I become more confident, independent; and I learned how to cook and can make my own decision for my own [sic]. (Respondent CU)

Respondent $\mathrm{Y}$ learned the way to organise oneself better in money management and self-planning,

Although we have the scholarship, the way we manage our money, plan for our daily lives or entertainment, the way we interact with others is a knowledge that we cannot learn through books or academic paper. (Respondent Y)

In terms of learning attitude, Respondent $\mathrm{Y}$ realised a change of attitude was needed after seeing her classmates' proactive attitude in learning by saying,

Learning attitude of my classmates was that they were very proactive in learning and always ask question when they don't understand something. Which makes me want to learn from them ... I realised I am not thinking critical enough. (Respondent $Y$ )

Respondents $\mathrm{P}$ and $\mathrm{YV}$ learned to express their opinion better via group work and small group discussion,

I am interested in the subject Introduction to Japanese Study, thus, I read the related articles to deepen my knowledge in this subject. The "Zemi group" (study group based on mutual interest) helps me in expressing my opinions. (Respondent P)

I learned how to express my opinions in the Japanese class during group work discussion. (Respondent YV) 
In the matter of friendship, Respondent $\mathrm{N}$ seemed to treasure friendship more than before by realising that,

Living alone make me realise that friends are very important. They are the one that help and comfort you when something happened when your family are not around. (Respondent $\mathrm{N}$ )

The respondents have learned various positive personal developmental aptitudes such as confidence, independence, better self-management, reading habit cultivation, critical thinking skills, desiring to gain more knowledge, learning to express oneself in group discussion and realising the importance of friendship.

At the interactive level, homestay programme and working part time are the two activities that the international students were encouraged to participate in where external outcomes can be observed. The International Students Centre of many universities organise homestay programmes to let students have a chance to stay a few days in a real Japanese family to gain a first-hand experience of how Japanese people are living their daily lives, cooking, doing household chores, using ofuro (Japanese way of bathing), sheeting futon as a bed to sleep and keeping them in the cupboard when they wake-up, learning the manners of eating by saying itadakimasu (literally means I humbly receive the food) before having a meal and saying gochisousamadeshita (literally means, thank you for the food) after the meal. Some of the manners they learned are internalised and become their habits subsequently.

During the stay, some of the host families may bring them to experience onsen (hot spring) which many Japanese enjoy. Respondent $\mathrm{C}$ describes the onsen experience as "awkward but definitely worth trying". Other host families may bring them to mingle around with the local people during the summer festival like, Bon Dance (a Japanese festival to honour the spirit of their ancestors) and at the same time, the historic meaning of the dance will be told. The good rapport built up by these activities can be life-lasting as appreciation notes and seasonal greetings exchanges will be followed-up after their stay.

Participating in community engagements such as visiting high schools, senior citizens or children' homes are another opportunity for the international students to interact with people of different ages in the society. Some of these activities may be eye opening for them as many of the Japanese elderly people who have retired stay healthy, energetic and efficacious in their retirement lives, particularly those who are involved in voluntarily work, mountain trekking and social dancing.

In this community activities, some of the students are asked to teach English to high school students or to make an oral presentation about their own country to promote cross-cultural understanding among Japanese people and school pupils. 
It was a really good experience for me to share my opinion in Japanese in front of lecturers and other Japanese students as well. (Respondent A)

I worked as a facilitator in World Language Center (WLC) in Soka University ... My work was to facilitate the Japanese students to have an English conversations in group ... made some new Japanese friends and help to improve my Japanese too. (Respondent S)

Some of them joined the voluntary work to help people who are in need such as to deliver food to people with visual impairment, to inspire children in orphan homes, to revitalise playgrounds as Respondent $\mathrm{P}$ recalled,

I volunteered in one of the old folk's home in Azabu, Tokyo. It was an unforgettable experience for it was not only about the work that I did there but also the memories and the advice that I received from the senior citizens. (Respondent P)

According to the rules set by the Ministry of Foreign Affairs, international students are permitted to work part-time, 28 hours per week or 8 hours per day during long-term school break as long as they applied for the working permit from the Regional Immigration Bureau of Japan. Many students take this working opportunity to refine their Japanese speaking and listening skills.

I realised that my listening and speaking skill improved through parttime job since I have to communicate with my boss and customer in Japanese [sic]. (Respondent A)

There are variety of part time jobs available for international students, particularly in the service lines such as in hotels, convenient store, café or restaurants. Just as the well-known Japanese business concept of "customers are always right", students learn the good value of how to serve their customers better in a polite way. The observation on Japanese working attitude is as important as part of their learning process.

I respect Japanese work commitment, e.g. say thank you to every bus passenger, guard - stand-up straight while on work. (Respondent YV)

I think through my part time job, I have come to appreciate the hard work of foreign labourers a lot more, and also those who are in the service industry. (Respondent E) 


\section{CONCLUSION}

Being given an opportunity to live alone abroad, immersed in the target language culture and society, without financial constraint, all respondents were free to do and learn what one wants; this optimum environment had yielded an abundance of significant outcomes from this study abroad programme. How much they have learned in terms of intercultural competence and self-development gains can be captured from their observations while interacting with Japanese people and others from various countries. The neoteric finding of this study is the behavioural changes the respondents reported in the self-narrations that resulted from one year stay in Japan. In the previous studies about student mobility and study abroad programmes (cf. Anderson et al. 2006; Messelink, Maele and Oatey 2015) the researchers were focusing on the impact of the programme in terms of students' personal growth and intercultural competence improvement but not in the domain of behavioural changes which can be served as meaningful insights to many educators. Salisbury $(2011,13)$ sees intercultural competency at individual level in two steps: the first "requires that one possess attitudes of respect or value for other cultures, openness and the ability to withhold judgement, and curiosity to discover while tolerating ambiguity". This first step at individual level is witnessed through their behavioural changes particularly related to interpersonal relationships, their sensitivity towards consideration of others' feelings, respect for the elderly people, appreciation of people around them, learning to tolerate and be patient with people from different cultures. These values may eventually lead to better chance of being employed if they put them into practice.

The second step necessitates "one [to] develop specific knowledge and comprehension that would include cultural self-awareness, deep cultural knowledge, and sociolinguistic awareness" (Salisbury 2011,13). This is materialised in terms of personal development where they realise that learning needs to be proactive and requires critical thinking, and expressing opinions needs to be supported by facts and statistics to validate one's opinion. Some of them have become good listeners during interaction and act appropriately according to the contexts and in their relationship with others.

As discussed earlier, the intercultural competency seen at the interactional level can be seen in the internal and external outcomes. Both outcomes culminate into an effective and appropriate communication and behaviour in an intercultural setting. Respondents who studied abroad are observant and sensitive to people or things that are new to them. They are open-minded, positive and diligent in learning new things. The majority of the respondents were happy and said they have benefited from a year of study abroad particularly in the domains of personal growth, Japanese and other cultural acquisitions and intercultural communicative skills. The respondents not only learned to observe and analyse contexts inside 
and outside the classroom, they were also able to internalise some good values and express them as seen in their behavioural changes.

The positive outcomes gained from the homestay, voluntary work and part time jobs gave them opportunities to mix around with people from different age groups. They learned to see things in a wider scope and appreciate people more regardless of their age and occupation; in other words, they seem to have grown more holistically as a person.

Another positive outcome which can be gained from the programme was the appreciation of one's own country, which may serve as a comprehensive patriotic dividend to a multi-ethnic country like Malaysia in the light of nationalism. Although Malaysia is a multiracial and multicultural country, it is still within Asia. With the exposure to foreign friendship and cultures from western countries such as, the United States and Europe - this made them learn and become aware of the world's diversity. Through the study abroad programme respondents came to acknowledge some of the uniqueness and positive sides of their own country and the advantages of being a citizen of that country. This integrated and holistic growth is definitely a bonus point to the Malaysian government from the national unity policy perspective.

The provision of a broader context and various learning environments to the respondents in this long-term programme reap rewards in a long run when these respondents join the work force.

However, based on the confusion and observation of social problems that occurred inadvertently during the students' stay in Japan, tertiary educators could have a sharing section for the respondents to share their experience of study abroad as encouragement and at the same time a counselling session for those who are confused or unsure of their behavioural changes.

It is recommended that the next cohort of students, who are going to Japan in the next study abroad programme, should be informed and trained to be more analytical in encountering issues that appear unconventional to them.

\section{ACKNOWLEDGEMENTS}

This study is sponsored by University of Malaya Research Grant (UMRG)-RG47715 HNE. 


\section{REFERENCES}

Anderson, P.H., L. Lawton, R.J. Rexeisen and A.C. Hubbard. 2006. Short-term study abroad and intercultural sensitivity: A pilot study. International Journal of Intercultural Relations 30(4): 457-469. https://doi.org/10.1016/j.ijintrel.2005.10.004

Benjamin, F.H. 2005. Gauging the impact of study abroad: How to overcome the limitations of a single-cell design. Assessment \& Evaluation in Higher Education 30(1): 3-19. https://doi.org/10.1080/0260293042003243869

Bennett, M. 2004. Becoming intercultural competent. In Toward multiculturalism: A reader in multicultural education, ed. J.S. Wurzel, 62-77. Newton, MA: Intercultural Resource.

Brooks, R. and J. Waters. 2009. International Higher Education and the Mobility of UK students. Journal of Research in International Education 8(2): 191-209. https:// doi.org/10.1177/1475240909105204

. 2010. Social networks and educational mobility: The experiences of UK students. Globalisation, Societies and Education 8(1): 143-157. https://doi. org/10.1080/14767720903574132

2011. International/transnational spaces of education. Globalisation, Societies and Education 9(2): 155-160. https://doi.org/10.1080/14767724.2011.576933

Deardorff, D.K. 2004. The identification and assessment of intercultural competence as a student outcome of internationalization at institutions of higher education in the United States. PhD diss., North Carolina State University.

2006. Identification and assessment of intercultural competence as a student outcome of internationalization. Journal of Studies in International Education 10(3): 241-266. https://doi.org/10.1177/1028315306287002

Dervin, F. and H. Layne. 2013. A guide to interculturality for international and exchange students: An example of hospitality? Journal of Multicultural Discourses 8(1): 1-19. https://doi.org/10.1080/17447143.2012.753896

Eurodesk. 2015. How can learning mobility of young people increase their employability? April. http://ec.europa.eu/education/library/publications/monitor 14_en.pdf (accessed April 2015).

European Youth Forum. 2013. The impact of non-formal education in youth organisations on young people's employability. http://issuu.com/yomag/docs/reportnfe_print (accessed April 2015).

Eurostat. 2019. Mobile students from abroad enrolled by education level, sex and country origin. https://appsso.eurostat.ec.europa.eu/nui/show.do?dataset=educ_ uoe_mobs02\&lang=en (accessed 22 February 2019).

Juvan, E. and M. Lesjak. 2011. Erasmus exchange program: Opportunity for professional growth or sponsored vacations? Journal of Hospitality \& Tourism Education 23(2): 23-29. https://doi.org/10.1080/10963758.2011.10697003

Messelink, H.E., V.J. Maele and H.S. Oatey. 2015. Intercultural competencies: What students in study and placement mobility should be learning. Intercultural Education 26(1): 62-72. https://doi.org/10.1080/14675986.2015.993555 
Salisbury, M.H. 2011. The effect of study abroad on intercultural competence among undergraduate college students. $\mathrm{PhD}$ diss., University of Iowa. https://doi. org/10.17077/etd.9rvi4i3z

Suzanne, E.B. 2015. International student mobility: The role of social networks. Social \& Cultural Geography 16(3): 332-350. https://doi.org/10.1080/14649365.2014.98 3961

University of Malaya Official Website. 2012. Annual report 2012. https://www.um.edu. my/about-um/media-centre/annual-report (accessed 20 February 2019).

. 2016a. Global planning and strategy centre. 18 February. http://um-staging. cloudapp.net/about-um/administration/chancellery/global-planning-andstrategy-centre (accessed 22 February 2019).

. 2016b. 3rd EU-Malaysia Higher Education Conference. UM Newsletter 20 April. https://www.um.edu.my/about-um/media-centre/news/2016/04/20/3rd-eumalaysia-higher-education-conference (accessed 20 February 2019).

Yorke, M. 2006. Employability in higher education: What it is - what it is not. York: Higher Education Academy. 